\title{
BUSINESS CYCLE SYNCHRONISATION IN THE GREEK REGIONS
}

\author{
Ioannis PANTELADIS, Maria TSIAPA \\ University of Thessaly, Greece
}

\begin{abstract}
This paper examines the degree of synchronicity in business cycles in Greek regions associated with specific spatial and economic characteristics that explain, to a large extent, synchronisation dynamics. We conducted an analysis of almost 30 years' (1980-2008) worth of data at the NUTSIII level (prefectures). We conclude that prefectures are more synchronised with the NUTSII regions than the national level, accentuating a regional (NUTSII) border effect. Moreover, the intensification of the integration process and the free operation of markets seem to diachronically affect the structural characteristics of the Greek regions and the geography of cyclical synchronisation. Our study revealed a two-stage integration in which in the first stage they are detected urbanisation economies, while in the second one localisation economies. The metropolitan region, apart from its prominent position in economic growth, shows a confined level of business synchronisation with the other regions, stressing Greece's pattern of economic and structural dualism.
\end{abstract}

Key Words: synchronization cycles, Greek regions, integration, econometric analysis

\section{Introduction}

The gradual deepening of integration has intensified the interaction and the interdependency between different areas and economies. At the same time the integration process has put border areas in a state of flux and has led to the aggravation of disparities between the less and the more developed regions. Regions with an inferior technologically productive system and a lower competitive position, such as Greece, have to tackle the pressure of global competition and exposure to international market forces.

In this context, Greece is characterised by an unequal spatial distribution of income, and an intensification of the regional disparities over time. Regional inequalities are based on the dominance of a metropolitan urban system, where the metropolitan region grows more rapidly than the national average. As a result, it has reaped pertinent advantages in terms of external economies, productive restructuring and extensive infrastructure improvement (Petrakos 2009).

The study on the influence of integration on economic growth is traditionally related to classical business cycles defined by absolute expansions and contractions of economic activity (Burns and Mitchell 1946). However, this relationship does not provide information on the tendency of economic fluctuations to become synchronised. Business cycle synchronisation is the co-movement of business cycles expressed in terms of deviations around an estimated trend (Lucas 1977). The degree of synchronisation of business cycle fluctuations among regions is conditioned upon some common structural characteristics, making the shocks and -cum- the fluctuations more symmetric. Consequently, the growth rate movements of some regions might be more or less synchronised, which is revealed by studying their synchronisation cycles.

This new aspect on the influence of integration on business cycle synchronisation has lately 
been the focus of considerable research. The vital role of production systems in the economy and the unprecedented changes they experience during integration require study of the evolution, transformation and determinants of synchronisation cycles. The systemically intensified influence of integration affects the backwardness, low levels of competitiveness and the inertia in structural changes that characterise the Greek regions, indicating the importance of studying the patterns and the potential determinants of synchronisation cycles in Greece. The literature on Greek business synchronisation cycles is limited and is focused mostly in the association of cycles with the European Union (EU). This paper fills this gap in detecting the business synchronisation cycles of the Greek regions by assessing and evaluating their spatial evolution over time and by appraising the amplitude of the association of business synchronisation cycles in the metropolitan area and the national average with the other regions.

This paper has two goals: to study the extent to which business cycles of the Greek regions are correlated and to investigate econometrically the determinants of the co-movement of output. The analysis outcomes are based on three salient points. First, the prefectures (NUTSIII regions) are more synchronised with the NUTSII regions than the national level, highlighting a regional (NUTSII) border. Second, there is a two-stage integration of Greek regions influencing on a differentiated way the synchronisation cycles, first by reinforcing urbanization economies and secondly by reinforcing localization economies. Third, the metropolitan region, apart from its prominent position of economic growth, displays a confined level of business synchronisation with the other regions, stressing the pattern of economic and structural dualism in Greece.

The paper is structured as follows. Section 1 summarises the literature. Section 2 details the methodology. Section 3 elaborates the synchronisation of regional cycles, and section 4 describes the geography of synchronisation. Section 5 detects the determinants of the co-fluctuations using an econometric approach. Finally, section 6 states the concluding remarks.

\section{Literature review}

The issue of synchronisation is of interest since many contemplated actions encourage questions about their cycles. In this section, we present some interesting contributions in the literature and emphasise their most crucial issues.

Most literature on business cycle synchronisation focuses on both the national and regional level. The investigation of the increasing or decreasing synchronicity of business cycles has been broadly studied with different data sets, spatial levels, time intervals or investigative methods. Various studies have concluded that European business cycles have become more synchronised (Artis and Zhang 1997, Barrios et al. 2003) amongst the more developed EMU members (Beine et al 2003); there is more synchronisation amongst EMU members compared to the European periphery (Beine et al. 2003); synchronisation has lately increased in some 'peripheral' countries (Marelli 2006); there are remarkable similarities between the business cycle patterns of countries, despite significant differences in the patterns of fiscal and monetary policies and terms of trade (Christodoulakis et al. 1995) and the cross-correlation of regions across national borders has increased over time (during the period 1979-1992 associated with the ERM implementation), while, simultaneously, cross-regional correlation within countries has decreased (Fatas 1997).

On the contrary, other studies allege for a less apparent evidence in the correlation of the cyclical movements (Harding and Pagan 2001) considering that the correlation of synchronised 
cycles remains low or even decreases in the case of the Greek regions (Montoya and de Haan 2007). In general, there are two streams of thought. The first supports the idea that economic integration leads to more symmetric fluctuations which, in turn, lead to more synchronised business cycles. The second agrees with Krugman (1991) and the notion that increasing integration will lead to regional concentration of industrial activities which, in turn, will lead to sector - or even region- specific shocks, increasing the likelihood of asymmetric shocks and diverging business cycles (Camacho et al. 2006). However, the bulk of the literature suggests increasing synchronicity (Marelli 2006).

The business cycle association among countries with inferior development characteristics and particularly with Greece and the EU has also been a subject of study. The results highlight the lack of cyclical convergence of Greece with the euro area (Gouveia and Correia 2008); a less synchronised cycle with the EU cycle after the introduction of the euro (Gogas and Kothroulas 2009); little sign of convergence (Crowley and Lee 2005); a low correlation of the business cycle with the Euro area business cycle and greater volatility (Papageorgiou et al. 2010); decreasing volatility over time and a weaker correlation and transmission in synchronisation of cycles with the Euro zone (Leon 2006); or a greater synchronisation with Algeria, Egypt and Tunisia than with other European countries (Gallegati et al. 2004).

Studies have examined not only to what extent business cycles have become similar but also the driving forces of the co-movement of output. The determinants that affect the synchronization cycles are various. First, the relative size (in terms of population) significantly affects economic co-fluctuations (Barrios and de Lucio 2003). Differences in industrial structure patterns and specialisation among regions are also important factors in business cycle synchronisation, as industry-specific shocks will generate a higher degree of business cycle synchronisation among regions with similar production structures rather than among regions with asymmetric structures (Imbs 2001). This is why industry-specific shocks usually play a more important role at the regional than the cross-national level (Belke and Heine 2006). Moreover, the integration process is believed to have a stronger effect on the synchronisation cycles in regions rather in countries due to intensified trade relations and specialisation levels (Tondl and Traistaru 2006). Some studies suggest the correlation of regional business cycles with the national cycle remains high over time in spite of European economic integration, inferring the existence of a border effect (Montoya and de Haan 2007), while others show that this effect has notably decreased (Barrios and de Lucio 2003). Concisely, the business cycle correlation should be studied with a multivariate approach, as it depends on a variety of factors, including structural and policy-related variables (Haan et al. 2008).

\section{Methodology}

Synchronicity is the co-movement of growth rates over time. Growth rates are measured as the rate of change in the real (inflation-adjusted) gross domestic product (GDP) per capita of a region. In our analysis for the estimation of business cycles in Greece, we use annual observations of the GDP in constant prices at the NUTS III Greek region level (prefectures), covering 29 years from 1980-2008. For the identification of the business cycle, we use the 'deviation cycle' proposed by Lucas (1977), which is defined as a cyclical fluctuation in the cyclical component of a variable around its trend. The 'deviation cycle' is identified by isolating the cyclical component from the trend component, and for this purpose, it is necessary to apply a specific de-trending technique, which transforms the non-stationary variable of regional output into a stationary one. There are a variety of filtering techniques to extract the cyclical components of the macroeconomic series. Most studies apply non-parametric filters divided into high-pass or low-pass filters, which remove high frequencies. 
We use the Hodrick-Prescott filter (1997), which estimates the trend component by minimising deviations from trend, subject to a predetermined smoothness of the resulting trend. It is a high-pass filter, it removes fluctuations with a frequency of more than eight years and puts those fluctuations in the trend (Haan et al. 2008). The advantages of this standard practice are first, that it is easy to implement and second, the resulting cyclical residuals are similar to those of the band-pass filter (Belke and Heine 2006, Haan at el 2008). We decompose the economic series of interest (the real GDP of Greek prefectures in log terms) into the sum of a slowly evolving secular trend, and a transitory deviation from it, which is classified as the following cycle:

Observed series $\left(X_{t}\right)=$ Permanent trend $\left(T_{t}\right)+$ Cycle $\left(Z_{t}\right)$

The HP filter has been widely used in business cycle literature. The filter extracts the trend $T_{t}$ from a given data $X_{t}$ by minimising the following function:

$$
\sum_{t=1}^{N}\left(X_{t}-T_{t}\right)^{2}+\lambda\left(\left(T_{t}-T_{t-1}\right)^{2}-\left(T_{t-1}-T_{t-2}\right)\right)^{2},
$$

where $X_{t}$ is the actual series, $T_{t}$ is the trend series and $\lambda$ is the smoothing parameter, which penalises the acceleration in the trend component relative to the business cycle component

$\left(x_{t}-\hat{T}_{t}\right)$. In other words, the $\lambda$ parameter controls the smoothness of the adjusted trend series $T_{t}$-, i.e., as $\lambda \rightarrow 0$, the trend approximate the actual series $X_{t}$, while as $\lambda \rightarrow \propto$, the trend becomes linear and thus deterministic. According to Marcet and Ravn (2003), the parameter $\lambda$, which is determined endogenously in annual data, should be between 6 and 7 , while according to Ravn and Uhlig (1997), it should be equal to 6.25.

The next methodology we employ calculates the cross-correlation coefficient to estimate the degree of linear co-movement of regions in different time series. For this purpose, we use the Pearson correlation coefficient for the cyclical part of the GDP. If the business cycle correlation coefficient has values around 1, it denotes full business cycle convergence, while if it has values around -1 , it suggests full business cycle divergence. Therefore, regions with low correlation coefficient are less synchronised and possess different economic structures (Kenen 1969). Nevertheless, low values of business cycle correlation should be interpreted carefully, as low synchronisation might instead just be an expression of agglomeration tendencies on a regional level and take place according to an optimising calculus (Belke and Heine 2006).

\section{The synchronisation of regional (prefectural) cycles}

For our analysis, we compute the correlation coefficients between the prefectural cycle (51 regions at NUTS III level) with first the national cycle and then with the cycle of the broader NUTSII regions (NUTSIII regions represent sub-regional units). The first method emphasises the co-fluctuating cycles among the prefectures and the national average, whereas the second method emphasises the interregional correlation coefficients to capture the regional specific border effect.

There are two approaches to analysing the correlation coefficient over time. The first splits the sample into various periods and examines the integration effect on each of them, and the 
second uses the rolling window technique to observe the evolution of the correlation coefficient (Massmann and Mitchell 2004). Instead of splitting the sample in arbitrary periods, we opt for using a rolling window of 8 years (Montoya and De Haan 2007). The results for the average correlation coefficient of all prefectures with both the national and the regional reference cycle are displayed in Figure 1. As shown, the average correlation of the prefectural cycle with the national cycle experienced a steep decline from 1990-2008. In contrast, the average correlation of the prefectural cycle with the regional cycle, despite the diminishing degree of synchronicity, remains higher than the correlation with the national cycle. Moreover, it recuperated slightly from 2001-2008.

On the basis of our findings, it becomes evident that there is a differentiated tendency regarding the degree of business cycle synchronisation. The discrepancy between the synchronisation of the prefectural cycle and the national and the regional cycle suggests that the integration process is more intensive at regional NUTS II level, as the cycle of the prefectures in Greece do not seem to co-fluctuate with the national cycle. The exception to that is the Attica region, where the business cycle proved to be synchronised with the national cycle, an outcome that could be attributed to the gradual concentration of an enormous part of the total economic activities in the region.

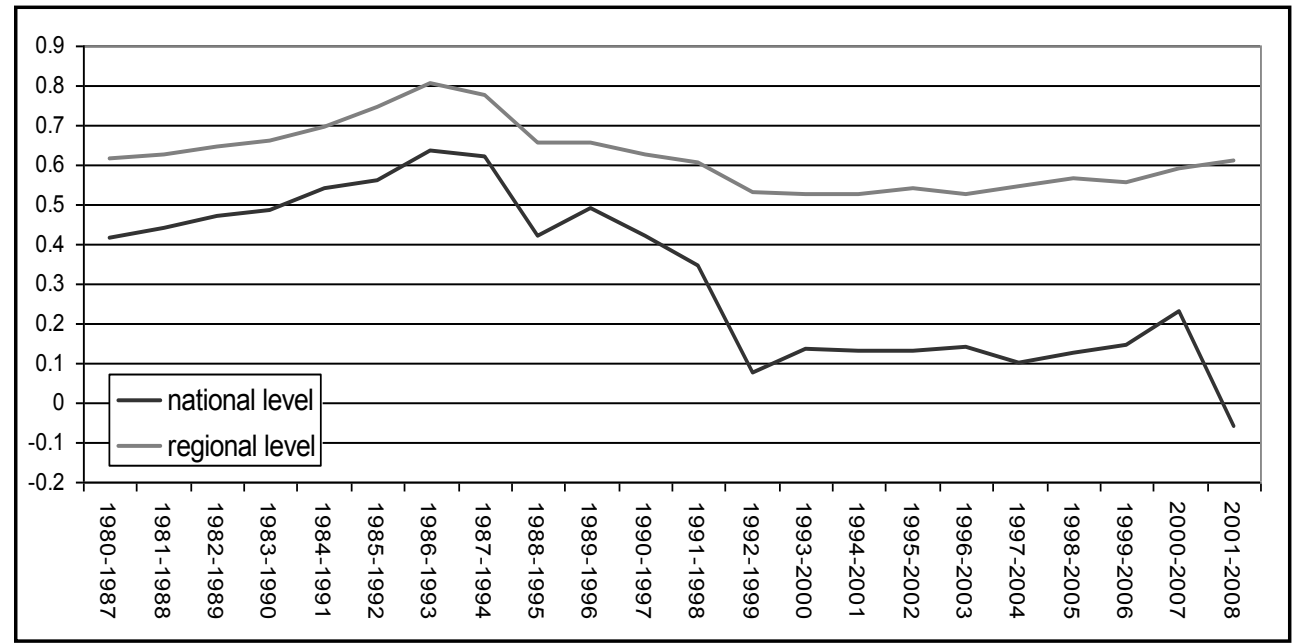

Fig. 1 - Prefectural (NUTSIII) cycle correlation with regional (NUTSII) and national business cycles. 8-year rolling window

The geography of synchronisation

It is interesting to investigate the correlation of the business cycles among the prefectures of different regions as well as the correlation among the prefectures of the same administrative region to pinpoint the degree of intraregional and interregional synchronisation at the NUTS III level. For this reason we applied a multidimensional scaling technique (MDS) to the cyclical components of the 51 prefectures (regions at NUTS III level). This technique converts a set of dissimilarity measures in several dimensions into two dimensions by minimising the squared sum of the difference between the real and the estimated distance. The purpose of the MDS is to provide a visual representation of the pattern of proximities among a set of objects 
represented by the business cycles of the prefectures.

From a more technical point of view, the MDS identifies a set of vectors in p-dimensional space, such that the matrix of Euclidean distances, which correspond as closely as possible to some function of the input matrix according to a STRESS (standardised residual sum of squares) function. The smaller the STRESS value, the better the representation. In our case, we use a two-dimensional configuration since the STRESS value is 0.005 , which denotes that the distances in the map represent, without distortions, the input data, so there is no need for higher dimensional configuration.

Figure 2 illustrates the prefectures that are closely located and shows that their business cycles are highly synchronised. We collect evidence by scrutinising whether these prefectures belong to the same region or to different regions. Apart from the regional (NUTSII) border effect, there are similarities, in terms of business cycle synchronisation, among prefectures of different NUTSIl regions, suggesting common characteristics with respect to both spatial and production structure. The identification of these common characteristics leads inductively to the next step, which is an econometric approach to synchronisation cycles.

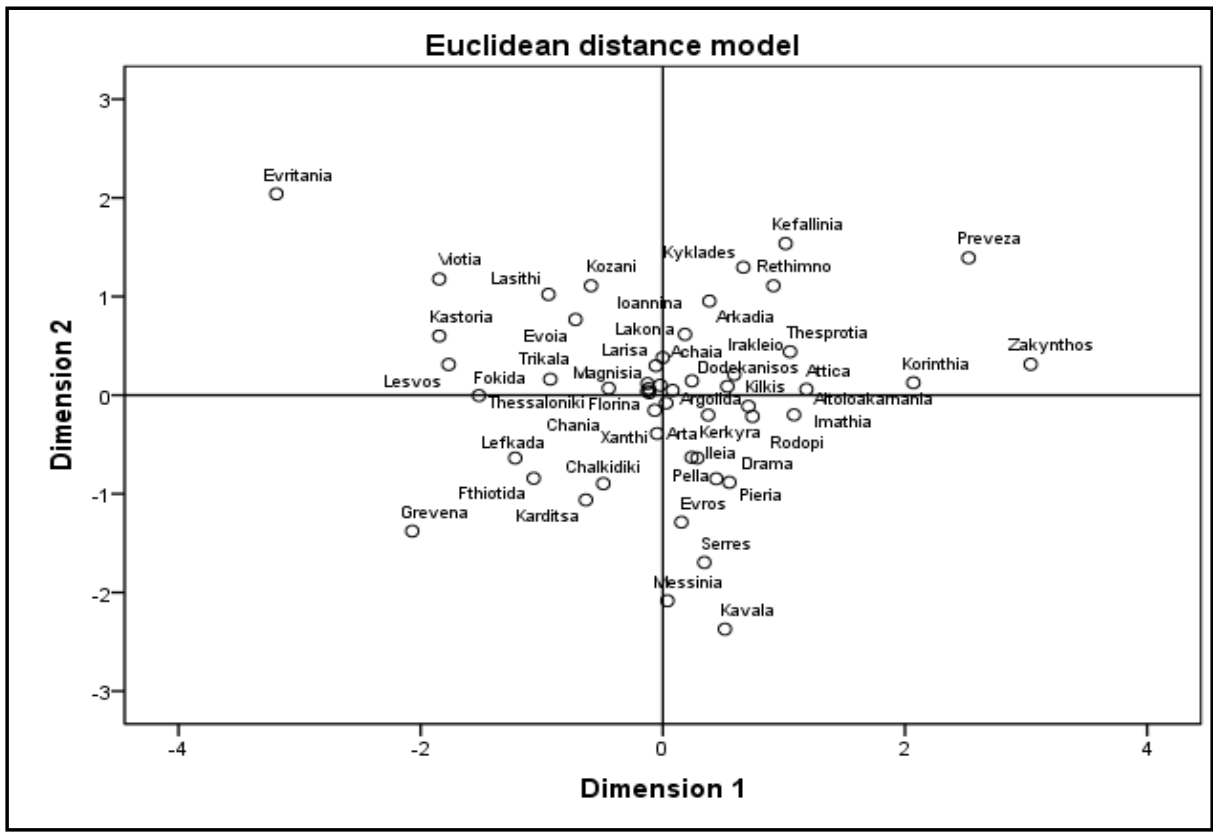

Fig. 2 - Multidimensional scaling NUTSIII region (1980-2008)

\section{Econometric analysis}

In this section our objective is to provide intuition on which and to what degree variables explain the different co-fluctuations cycles in the Greek regions. Specifically, our econometric analysis is based on three important points: First, we use an interdisciplinary approach and compile a multivariate model, which investigates a series of industrial and regional-specific factors affecting the synchronicity of business cycles between two prefectures (NUTS III regions). Second, our research examines the cross-correlation of all possible region-pairs with 
each other. Third, the study span from 1980 to 2008 is divided into two separate time intervals, 1980-1992 and 1993-2008, to appraise the differential consequences of integration dynamics. The first sub-period is marked by Greece's accession to the EU (1981), and the second is marked by the completion of the Single European Market (SEM), which steered the local economies to unprecedented economic and structural changes. This division into the two subperiods considers the Maastricht treaty and the creation of the EU (the European Community successor) as watersheds since studies of business cycle synchronisation identify a "Maastricht effect" associated with the further deepening of European integration (Altavilla 2004). Therefore, this paper attempts to disentangle the effects of the two-stage integration of Greece on its regional co-fluctuations cycles.

In order to be identified the driving forces of the co-movement of output, we compile and estimate a gravity econometric model with the following form: $Y_{i j t}=\alpha_{0}+\sum_{r=1}^{n}\left(\alpha_{r} X_{r i t}\right)+\varepsilon_{i j t}$, where $Y_{i j t}$ is the dependent variable, $\alpha_{0}$ is the constant term; $\sum_{r=1}^{n} X_{\text {rit }}$ is a set of determinants, $\sum_{r=1}^{n} a_{r}$ is a set of the estimators of determinants; $e_{i j t} N\left(0, \sigma^{2}\right)$ is the disturbance term (with 0 mean $r=1$ and constant variance); $i$ and $j$ denote the region-pairs; $r$ denotes the independent variables that are $1-n\left(1^{\eta}, \ldots, n^{\eta}\right)$; and $t$ is the time period under consideration. The model studies the 51 Greek NUTSIII regions that correspond to the administrative units of prefectures and separately estimates two sub-periods (1980-1992 and 1993-2008) to perceive and assess peculiar integration effects in the regions during the two periods of EU and SEM accession. All data are from the Hellenic Statistical Authority.

Analytically, the econometric model to determine business synchronisation cycles is as follows:

$$
\begin{aligned}
& \rho\left(\tilde{y}_{i}, \tilde{y}_{j}\right)_{t}=a_{o}+b_{1} I S I M_{i j t}+b_{2} I S I M_{i j t} T_{E R T} T_{i j t}+b_{3} S P E C_{i j t}+b_{4} S P E C_{i j t} C A P_{i j t}+b_{5} L I N K_{i j t}+
\end{aligned}
$$

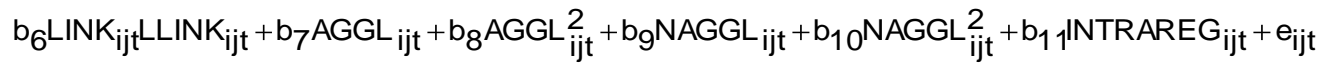

The dependent variable $\rho\left(\tilde{y}_{i}, \tilde{y}_{j}\right)$ denotes the business cycle correlation between regions $i$ and j over time period t. Business cycle synchronisation is defined bilaterally as the contemporaneous correlation of cyclical components of the real GDP of two regions. Following Frankel and Rose (1998), the business cycle synchronisation is measured bilaterally by computing the simple contemporaneous correlation between cyclical components of annual real GDP for region i and j over the time span t. Our econometric model's results are obtained by running two different regressions applied in two distinct non-overlapping time periods (19801992 and 1993-2008 correspondingly).

The independent variables were analysed as follows: First, the index of similarity in production (ISIM) was introduced in the econometric model following Kenen's (1969) conventional hypothesis that the dissimilarity of sectoral specialisation patterns has long been recognised as a potential source of asymmetric shocks or, inversely, that greater similarity in production will increase business cycle synchronisation. The variable is defined as the index of dissimilarity (proposed by Petrakos and Jackson 2001):

$$
\operatorname{ISIM}_{\mathrm{ijt}}=-\sum_{\mathrm{s}}\left(\left(\mathrm{i}_{\mathrm{st}}-\mathrm{j}_{\mathrm{st}}\right)^{2}\right),
$$

where $\mathrm{i}$ and $\mathrm{j}$ are the regions under comparison in the period $\mathrm{t}$ for the industrial sectors $\mathrm{s}$. In Greece, a de-industrialisation process began in the 1980s, became more pronounced in the 
second half of the 1990s and even more dramatically in the dawn of the new millennium (Petrakos et al. 2007). This sweeping restructuring of the productive base resulted in an increase in the share of services. As a consequence of these systemic changes, the index of similarity is expected to be positively related to the synchronisation cycles. The main argument is that the gradual decrease of primary and secondary sectors in favour of the increasing share of the tertiary sector fosters the similarity of the productive base among regions and thus making the shocks and business cycles fluctuations more symmetric.

However, the spatial-economic system of Greece needs to be taken into account. This system is dominated by two metropolitan regions, Athens and Thessaloniki. In several cases, the metropoles have resumed the dynamic that existed previously (in the 1980s) due to industrial activities, which are the result of the increasing significance of the tertiary sector. This, nevertheless, raises the question of what kind of structural changes are going to be experienced by the remaining small and medium-sized cities, which, due to their confined market size and economic potentials, specialise either in primary or secondary activities. For this reason, the similarity index in the econometric model is related to the share level ${ }^{1}$ of the tertiary, or secondary, sector (TERT or SEC) to estimate the impact of specialisation similarity on the co-fluctuation of business cycles. The hypothesis tested is that the level and type of specialisation matter for synchronisation cycles.

Specialisation may affect the business cycle differently depending on the sectoral breakdown (Barrios et al. 2001) that, in fact, captures the idiosyncrasies of the production systems under transformation. This suggests that the influence of productive similarity on the co-fluctuations cycles should be appraised not only at the broader sectors of the total economic activity but also at a more disaggregated level. Following several studies that attest that industry-specific shocks are more important determinants of synchronisation cycles at regional rather than at national level (Clark and Shin 2000), we decided to include in our econometric model a similarity in manufacturing specialisation (SPEC) variable, which is indicated as the minus sign of the specialisation distance between two regions $\mathrm{i}$ and $\mathrm{j}$ :

$$
\text { SPEC }_{i j t}=-\mid \text { SPEC }_{i t}-\text { SPEC }_{j t} \mid \text {, }
$$

where a region's specialisation index $\left(\mathrm{SPEC}_{\mathrm{it}}\right)$ is measured using the relative Theil index ${ }^{2}$ (Theil 1967), and estimated for the two-digit manufacturing sectors. High values for the manufacturing specialisation in a region-pair suggest similarities in their manufacturing structure. This similarity transmits the sector-specific shocks into the real economy of the region-pairs, thus, activating symmetric business cycle co-fluctuations.

In the same vein with the variable of similarity, we associate, pari passu, the manufacturing specialisation with the share of the dominant manufacturing sector. To better deduce and illustrate the results, the manufacturing sector was grouped into three sectors: the consumer, intermediate and capital sectors (see Petrakos and Tsiapa 2000). The manufacturing specialisation variable is associated with the manufacturing sector share ${ }^{3}$, namely, the consumer sector (CON), which signifies the labour-intensive production base or the capital sector (CAP), the capital-intensive production base. The positive association of the common specialisation pattern with the business cycle correlation (Belke and Heine 2006) leads to the expectation of a positive relation with the manufacturing specialisation variable conditioned upon the share of the aforementioned sectors.

A similarity in input-output linkages (LINK) variable is also included in the econometric model. This variable measures the degree to which manufacturing uses imported inputs and indicates the development of synergies among the economic units as a result of their 'forward 
and backward' linkages. It is indicated as the minus sign of the distance of the input-output linkages between two regions in the manufacturing sector:

$$
\mathrm{LINK}_{\text {ijt }}=-\left|\mathrm{LINK}_{\text {it }}-\mathrm{LINK}_{\mathrm{jt}}\right| \text {, }
$$

where $L_{I N K_{i t}}=\frac{Q_{i t}}{V A_{i t}}$, where $i$ denotes the region, $Q$ the output and VA the value added (Forslid et al. 2002). High values for this variable suggest the existence of vertical, or input-output, linkages between manufacturing industries, where industries are provided with raw materials or semi-finished products for their final goods. However, similarity in the input-output linkages suggests that this might occur at a high or low level of values. For this reason, it is related to the average variable in the input-output linkages between two regions (LLINK). The inputoutput linkages within this line of thought, are expected to correlate positively with the synchronisation cycles.

Agglomeration economies refer to various forms of clustering of economic activities. In our case, clustering of economic activities can be found at the specific level of aggregation associated with the considerable variation in economic size of the geographical units (regions/cities) and, hence, with an uneven distribution of economic activities (density) across space. Agglomeration economies are represented in the econometric model by two variables of economic density (which is more accurate than size, Ciccone and Hall 1996). The first variable is dissimilarity in agglomeration economies (AGGLD), which is the distance in agglomeration between two regions:

$$
A G G L D_{i j t}=\left|A G G L_{i t}-A G G L_{j t}\right| \text {, }
$$

where $A G G L$ is estimated using the ratio of the output to the area size: $A G G L_{i}=Q_{i} / A_{i}$ and where $i$ denotes the region, $Q$ the output and $A$ the area.

The second variable for agglomeration economies is dissimilarity in neighbouring agglomeration economies (NAGGLD), which is estimated by the distance in spatial agglomeration of neighbouring regions that are adjacent to the regions-pairs $\mathrm{ij}_{\mathrm{ij}}$ :

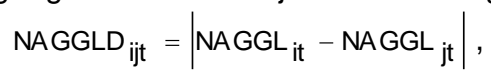

where NAGGL is estimated using the ratio of the sum of the output of all neighbouring regions to their total area size: $N A G G L_{i}=\Sigma Q /$, where $Q$ is the total output and $A$ the total area size of $\sum_{\mathrm{r} A}^{\mathrm{r}}$

the neighbouring regions $r$ of the regions-pairs $\mathrm{sij}_{\mathrm{ij}}$ respectively. The AGGL and NAGGL variables refer to the intraregional and interregional externalities respectively. According to Ciccone and Hall (1996), the density of economic activity is a source of enhanced productivity gains due to the effect of spatial externalities leading to increasing returns within regions. Furthermore, any increase of economic density creates a multiplier effect in productivity by influencing or steering eventually economic growth cycles. For this reason, we investigate the non-linear relationship of the agglomeration economies (Segal 1976) with the synchronisation cycles by including both the agglomeration and neighbouring agglomeration economies in monad and quadratic power in the econometric model. We assume there could be a critical threshold where differences in intraregional and interregional agglomeration economies affect the business synchronisation cycles between the regions through the differentiated functional impact of these mechanics.

Finally, we include the REG variable as a dummy that defines whether NUTSIII regions are members of the same broader NUTSII region. The positive contribution of this variable suggests the existence of a regional border effect. 
We evaluate the econometric model determinants using a cross-section regression, one for each period, and the WLS (weighted least squares) method in order heteroscedasticity to be corrected. The results of the econometric model are displayed in Table 1. More analytically, for the first sub-period, the correlation of the index of similarity in production (ISIM) with the synchronisation cycles is positive and statistically significant by the condition of a high share in the dominant sector, which, in this case, is the tertiary sector (the secondary displays low statistical significance, equation 2 of Table 1):

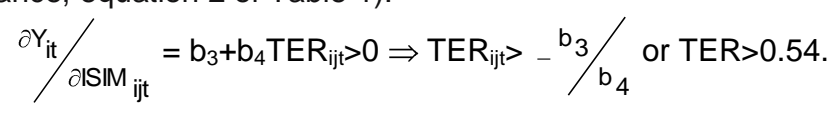

The similarity in manufacturing specialisation is shown to depend on the factor-intensity, which, in this case, is the capital sector (the consumer displays low statistical significance). Thus, the variable contributes positively and statistically significantly to the dependent variable by the condition of a high capital share:

$$
\partial Y_{i t} / \partial S_{i j t}=b_{3}+b_{4} C_{i j t}>0 \Rightarrow C A P_{i j t}>-b_{3} / b_{4} \text {, or } C A P>9.59 \text {. }
$$

Both types of productive similarities in the tertiary and capital (from the manufacturing) sectors illustrate the supremacy of regions with a diversified productive base and an advanced technologically productive system. The effect of the similarity in input-output linkages in the synchronisation cycles is positive and statistically significant (for every level of values), suggesting the considerable role of vertical integration in the business co-fluctuations of regions:

$$
\partial Y_{i t} / \partial L_{I N K_{i j t}}=b_{3}+b_{4} L L I N K_{i j t}>0 \Rightarrow L_{L I N K_{i j t}>-} b_{3} / b_{4} \text { or LLINK>-0.25. }
$$

Regarding the dissimilarity in agglomeration economies, an inverted U-shaped curve shows that, over a certain level, its effect on the synchronisation cycles is negative:

$$
\partial Y_{i j t} / \partial A G G L D_{i j t}=b_{3}+2 b_{4} A G G L D_{i j t}>0 \Rightarrow A G G L D_{i j t}>{ }_{-} b_{3} / 2 \cdot b_{4} \text { or } A G G L D>719.18 .
$$

That means that beyond a threshold, the intraregional agglomeration dissimilarities negatively affect business cycle synchronisation among prefectures (NUTS III regions), as the dissimilarities in question reflect the differentiation in the structural characteristics among regions. The dissimilarity in neighbouring agglomeration economies displays statistically insignificant relation to the correlation coefficients of the business cycles. Finally, the regional dummy variable is positively related to and statistically significant for cycle synchronisation. Obviously, the cycle convergence increases in prefectures in the same NUTS II region.

The econometric results for the second sub-period (1993-2008) accentuate the following peculiarities in the business synchronisation cycle determinants in Greek regions: First, the correlation of the index of similarity in production (ISIM) with the synchronisation cycles is positive by the condition of a high share in the secondary sector:

$$
\partial Y_{i t} / \partial \mid S_{\mid M}=b_{3}+b_{4} S_{i j t} C_{i j t}>0 \Rightarrow S E C_{i j t}>-b_{3} / b_{4} \text { or SEC }>0.28 \text {. }
$$

Second, the effect of the similarity in manufacturing specialisation seems to be dependent on the consumer sector share:

$$
\partial \mathrm{Y}_{\mathrm{it}} / \partial \mathrm{SPEC}_{\mathrm{ijt}}=\mathrm{b}_{3}+\mathrm{b}_{4} \mathrm{CON}_{\mathrm{ijt}}>0 \Rightarrow \mathrm{CON}_{\mathrm{ijt}}>-b_{3} / b_{4} \text { or } \mathrm{CON}>68.49 \text {. }
$$

Thus, it confirms the hypothesis that specialisation matters to the business co-fluctuations of 
regions and specifies the form of specialisation in regions with a labour-intensive productive structure. Third, the relation of the dissimilarity in neighbouring agglomeration economies is presumably negative and statistically significant for the synchronisation cycles, whereas the effect of the dissimilarity in agglomeration economies to the dependent variable seems to have faded. The results also support an inverted U-curve relation between the dissimilarity in neighbouring agglomeration economies with the dependant variable, where, over a critical value, this effect becomes negative:

$$
\partial Y_{i j t} / \partial N A G G L D_{i j t}=b_{3}+2 \cdot b 4 N A G G L D_{i j t}>0 \Rightarrow N A G G L D_{i j t}>{ }_{-} b_{3} / 2 \cdot b_{4} \text { or NAGGLD }>2318.18
$$

It is apparent that, in the second sub-period, where the integration process has proceeded gradually, the synchronisation cycles of the pair-regions are influenced by the dissimilarity agglomeration effects generated by neighbouring regions. That means that the differences in the neighbouring agglomeration impact on the prefectures matters for their differential business cycle fluctuations. Fourth, the relation of the similarity in input-output linkages to the synchronisation cycles roved to be positive and statistically significant under the condition of a high level of linkages:

$$
\partial Y_{i t} / \partial L_{I N K}=b_{3}+b_{4} L_{i j t} L I N K_{i j t}>0 \Rightarrow L_{L I N K} K_{i j t}{ }_{-} b_{3} / b_{4} \text { or LLINK }>0.18
$$

Finally, the coefficient estimator of the regional dummy variable maintains the positive value, as well as its statistically significant sign at the second sub-period implying the existence of regional border effect.

\section{Conclusions}

This paper attempts to identify the pattern of business synchronisation cycles in Greek regions and the attractors of regional co-fluctuations due to the integration process. The econometric analysis split the time period into two distinct intervals, which accentuated a series of important idiosyncrasies between these two sub-periods associated with the dynamics of integration and the regions' structural characteristics.

During the first sub-period characterised by the accession of Greece in the EU, the gradual regional integration-cum-incipience of the de-industrialisation process triggered important structural and urban transformations. This paper attests that similar levels of agglomeration economies drive co-fluctuations of the economic cycles among the big urban centres. Furthermore, co-fluctuated regions are those that are specialised in the tertiary sector and/or the capital-intensive manufacturing activities indicating the existence of urbanisation economies.

On the contrary at the second sub-period coincided with the completion of the SEM and the creation of the EU, there is a second-stage integration, which affected the medium-sized regions. Obviously, the deepening of European integration adversely affected the industrial structure of Greek regions, which is reflected in the gradual dominance of labour-intensive activities. In that sense, the business cycles of the medium-sized regions seem to be synchronised by the shock of this transition into light industry, which was quasi-symmetric across regions. Moreover, the size of these regions did not allow them to develop a diversified 
Table 1

Results of the econometric model of business synchronization cycles in the Greek regions, 1980-2008 (cross-section WLS model)

\begin{tabular}{|c|c|c|c|c|}
\hline Independents & \multicolumn{2}{|c|}{ period: $1980-1992$} & \multicolumn{2}{|c|}{ period: $1993-2008$} \\
\hline & (1) & (2) & (3) & (4) \\
\hline ISIM & -5.52 & -1.52 & $-3.73\left(^{* * *}\right)$ & $-3.26\left(^{* * \star}\right)$ \\
\hline ISIM TER & $10.18\left(^{*}\right)$ & & & $-11.22\left({ }^{\star \star \star}\right)$ \\
\hline ISIM SEC & & $-2.23\left(^{*}\right)$ & $12.96\left(^{* * *}\right)$ & \\
\hline SPEC & $-0.14\left(^{*}\right)$ & $-0.08\left(^{*}\right)$ & -0.22 & -0.02 \\
\hline SPEC CAP & $0.01\left(^{* * *}\right)$ & & & -0.0001 \\
\hline SPEC CON & & $-0.007\left(^{* * *}\right)$ & $0.003\left(^{*}\right)$ & \\
\hline LINK & $1.37\left(^{* * *}\right)$ & $0.41\left(^{* * *}\right)$ & $-2.69\left(^{* *}\right)$ & $-2.18\left(^{* *}\right)$ \\
\hline LINK LLINK & $0.35\left({ }^{* * *}\right)$ & $0.18\left({ }^{* * *}\right)$ & $0.48\left(^{*}\right)$ & $0.75\left(^{*}\right)$ \\
\hline AGGLD & $0.002\left({ }^{* *}\right)$ & 0.002 & -0.0002 & -0.0002 \\
\hline $\mathrm{AGGLD}^{\wedge} 2$ & $-1.4610^{-6}\left({ }^{* *}\right)$ & $-1.3210^{-6}$ & $-1.6510^{-8}$ & $-1.4510^{-8}$ \\
\hline NAGGLD & 0.0002 & 0.0002 & $0.0001\left(^{*}\right)$ & $0.0001\left(^{*}\right)$ \\
\hline NAGGLD^2 & $-5.3710^{-8}$ & $-1.1710^{-1}$ & $-3.3010^{-8}\left({ }^{*}\right)$ & $-2.4610^{-8}\left({ }^{*}\right)$ \\
\hline INTRAREG & 0.11 & 0.09 & $0.18\left(^{* * *}\right)$ & $0.18\left(^{* * *}\right)$ \\
\hline $\mathrm{R}^{2} \mathrm{adj}$ & 0.36 & 0.21 & 0.11 & 0.10 \\
\hline $\bar{F}$ & 68.26 & 58.26 & 15.46 & 13.61 \\
\hline $\bar{N}$ & 1275 & 1275 & 1275 & 1275 \\
\hline
\end{tabular}

${ }^{* * *}$ statistically significant at $1 \%$ level, ${ }^{* *}$ statistically significant at $5 \%$ level, ${ }^{*}$ statistically significant at $10 \%$ level

productive base that could lead to the development of localization economies. The extended de-industrialisation of this sub-period and the poor inherited endowments of regions did not steer them to specialise in sectors with increasing returns. Furthermore, at a higher spatial level, it has been alleged that the international globalisation of markets has led to a more pronounced labour-intensive specialisation in southeastern Europe (Midelfart et al. 2002).

Regarding the economic activities in all sectors, a similar distributional pattern seems to positively affect the synchronicity of the cycles when they are included in the analysis of the average level of either the tertiary or secondary sector shares of the region-pairs. We show that the positive impact of the secondary sector on business cycle synchronicity is associated with construction activities. The latter is either a complementary activity or a substitute for the diminishing industrial performances triggering the growth process of Greek regions mostly in the second sub-period.

The dissimilarities of intra-regional agglomeration economies among the region-pairs are not significant in the second sub-period and seem, instead, to be more important to the 
interregional agglomerations of neighbouring regions. The deepening process of integration that, inter alia, is associated with building transport and communication infrastructures could explain this. In that sense, spatial integration fosters mainly the interdependence of adjacent regions and thus the redistribution of economic activities. Consequently, the degree of dissimilarity among the interregional agglomeration economies start affecting the business cycle synchronisation between region-pairs conditioned upon the size of the agglomeration differences between their neighbouring regions.

Finally, we make the salient point that business cycles in metropolitan regions in the second sub-period are not synchronised. This reflects the separate route of the metropolitan regions that affects their business cycle synchronisation. The low degree of synchronisation could be an expression of their differential urbanisation economies, which explains the expansion of Attica that took place at the expense of the other regions in Greece. From this point of view, these developments could be interpreted as a further gap in the distributional pattern of economic activities across space and as a perpetuation of the structural dualism of Greece.

\section{Endnotes}

1. For each pair of regions the share is emanated from the average shares of the two under study regions.

2. It is calculated by the equation:

$$
S P E C_{i}=\sum_{j=1}^{J} a_{j}(i) \ln \left(\frac{a_{j}(i)}{a_{j}}\right)
$$

with $0 \leq T_{i} \leq \ln \left(1 / a_{j}^{*}\right), \quad a_{j}^{*}$ as the minimum value in the range of values $\alpha_{j} ; i$ denotes the studied region, $J$ indicates the total number of branches in which region i specialises and $a_{j}^{*}$ is the share of each branch in the studied area. The merits of the Theil index are described broadly in the literature as it is neither scale nor mean dependent, it is not excessively affected by extreme values, it is independent of the number of regions and it is decomposable in between-group and within-group coefficients.

3. For each pair of regions the share is emanated from the average shares of the two under study regions.

\section{References}

ALTAVILLA, C. (2004), Do EMU Members share the same Business Cycle?, Journal of Common Market Studies 42, pp.869-898.

ARTIS, M. and ZHANG, W (1997), International Business Cycles and the ERM: Is There a European Business Cycle?, International Journal of Finance and Economics, vol. 2(1), pp. $1-16$.

BARRIOS, S. and LUCIO, J. (2003), Economic Integration and Regional Business Cycles: Evidence from the Iberian Regions, Oxford Bulletin of Economics and Statistics, vol. 65 (4), pp. 497-515.

BARRIOS, S. BRÜLHART, M., ELLIOTT, R. and SENSIER, M. (2001), A Tale of Two Cycles: Co-fluctuations Between UK Regions and the Euro Zone, Discussion Paper, 0101, The University of Manchester.

BEINE, M., CANDELON, B. and K.SEKKAT (2003), EMU membership and business cycle phases in Europe: Markov-swiching VAR analysis, Journal of Economic Integration, 18, pp. 214-242.

BELKE, A. and HEINE, J. (2006), Specialisation patterns and the synchronicity of regional employment cycles in Europe, International Economics and Economic Policy, vol. 3(2), pp. 91-104.

BURNS, A. and WESLEY M. (1946), Measuring Business Cycles, New York, National 
Bureau of Economic Research, Studies in Business Cycles, vol. 2.

CAMACHO, M. PEREZ-QUIROS, G. and SAIZ, L. (2006), "Do european business cycles look like one?", Computing in Economics and Finance 2006, 175, Society for Computational Economics.

CHRISTODOULAKIS, N., DIMELIS, S., and KOLLINTZAS, T. (1995), Comparisons of business cycles in the EC: Idiosyncacies and regularities, Economica, 62, pp.1-27.

CICCONE, A. and HALL, R. (1996), Productivity and the Density of Economic Activity, The American Economic Review, 86(1), pp. 54-70.

CLARK, T.,E., SHIN, K. (2000), The sources of fluctuations within and across countries, in: Hess, G., van Wincoop, E. (eds), Intranational Macroeconomics. Cambridge University Press, Cambridge, pp.189-217.

CROWLEY, P., \& LEE, J. (2005), Decomposing the co-movement of the business cycle: A time-frequency analysis of growth cycles in the euro area, Bank of Finland discussion papers 12/2005.

FATÁS, A. (1997), EMU: Countries or regions? Lessons from the EMS Experience, European Economic Review, 41, pp. 743-751.

GALLEGATI, M., GALLEGATI, M., \& POLASEK, W. (2004), Business cycle fluctuations in Mediterranean countries (1960-2000), Emerging Markets Finance and Trade, 40(6), pp. 28-47.

GOUVEIA, S., \& CORREIA, L. (2008), Business cycle synchronization in the Euro area: the case of small countries, International Economics and Economic Policy, 5(1), pp. 103-121.

HAAN, J., INKLAAR, R. and JONG-A-PIN, R. (2008), Will business cycles in the euro area converge? A critical survey of empirical research, Journal of Economic Surveys, vol. 22, No 2, pp. 234-273.

HARDING, D. and PAGAN, A. (2001), Extracting, Using and Analysing Cyclical Information, MPRA Paper 15, University Library of Munich, Germany.

HODRICK, R. and PRESCOTT, E. (1997), Postwar U.S. Business Cycles: An Empirical Investigation, Journal of Money, Credit, and Banking, 29 (1), pp.1-16.

IMBS, J. (2001), Co-Fluctuations, CEPR Discussion Paper, No. 2267.

KENEN, P. (1969), "The Theory of optimum Currency Areas: An Eclectic View", in R. Mundell and A. K. Swoboda (eds.) Monetary Problems of the International Economy, University of Chicago Press, 41-60.

KRUGMAN, P. (1991), "Increasing returns and economic geography", Journal of Political Economy, vol. 99, pp.484-499.

LEON, K. (2006), The European and the Greek business cycles: Are they synchronized?, MPRA paper no. 1312.

LUCAS, R. (1977), Understanding business cycles, Stabilization of the domestic and international economy, Carnegie-Rochester Conference Series on Public Policy, pp.7-29.

MARCET, A. and RAVN, M. (2001), The HP-Filter in Cross-country Comparisons, Economics Working Papers 588, Department of Economics and Business, Universitat Pompeu Fabra.

MARELLI, E. (2006), Specialisation and Convergence of European Regions, The European Journal of Comparative Economics, vol. 4 No 2, pp.149-178.

MASSMANN, M. and MITCHELL, J. (2003), Reconsidering the evidence: Are Eurozone business cycles converging?, Working paper B-05, Center for European Integration Studies, Universität Bonn.

MIDELFART-KNARVICK, K.H., OVERMAN, H.G., REDDING, S.J. and VENABLES, A.J. (2002), Integration and Industrial Specialization in the European Union, Revue Economique, 53 (3), pp. 469-481.

MONTOYA, L. and De HAAN, J. (2007), Regional business cycle synchronization in Europe?, Bruges European Economic Research Paper 11, International Economics and 


\section{Economic Policy.}

JACKSON, M. and PETRAKOS, G. (2000), Industrial Performance Under Transition: The Impact of Structure And Geography, Discussion paper, University of Thessaly, Department of Planning and Regional Development, 6(5).

PAPAGEORGIOU, T., MICHAELIDES, P. and MILIOS, J. (2010), "Business cycles synchronization and clustering in Europe", Journal of Economics and Business, 62, pp.419. 470.

PETRAKOS, G. and TSIAPA, M. (2000), 'The evolution and structure of industry', in G. Petrakos (ed), The Development of Balkans. Volos: University Press.

PETRAKOS, G., FOTOPOULOS, G. and KALLIORAS, D. (2007), A southern perspective on economic integration and structural change, in Krieger-Boden C., Morgenroth E. and Petrakos G. (eds): The Impact of Economic Integration on Regional Structural Change and Cohesion, London: Routledge, pp. 72-95.

PETRAKOS, G. (2009), Regional inequalities and selective growth: the economic dynamics of space and the preconditions of implementation effective policy, in: 25 papers for the planning and the development of space, University of Thessaly Press (in Greek).

RAVN, M. and UHLIG, H. (1997), On Adjusting the HP-Filter for the Frequency of Observations, Review of Economics and Statistics, 84(2), pp. 371-376.

SEGAL, D. (1976), Are there returns to scale in city size?, Review of Economics Statistics, 58, pp. 339-450.

THEIL, H. (1967), Economics and Information Theory: Studies in Mathematical and Managerial Economics, Skokie: Rand McNally.

TONDL, G. and TRAISTARU-SIEDSCHLAG, I. (2006), Regional growth cycle convergence in the European Union, The Economic and Research Institute, working paper, No 173.

Initial submission, June 5, 2011

Revised submission, September 10, 2011

Final acceptance, November 30, 2011

Correspondence: Department of Planning and Regional Development, University of Thessaly, School of Engineering, Pedion Areos, Volos, 383 34, Greece.

E-mail: mtsiapa@prd.uth.gr 
